\title{
Comparison of Tension Stiffening Models for High Strength Concrete Beams
}

\author{
Min Sook Kim, Young Hak Lee* \\ Kyung Hee University \\ 1732 Deogyeong-daero, Yongin, Korea \\ kimminsook@khu.ac.kr; leeyh@khu.ac.kr*
}

\section{Extended Abstract}

The concrete is assumed to carry no tension at the crack. However, the intact concrete between adjacent cracks can still carry some tensile stresses due to the bond between reinforcement and surrounding concrete. Tension stiffening should be considered as one of the important factors to predict realistic behaviours of reinforced concrete members. Allam et al. proposed simple analytical procedure based on commercial finite element program [1]. Perera and Mutsuyoshi performed on direct tension test to evaluate tension stiffening effect for high strength concrete members [2]. The objective of this paper is to compare the deflections obtained from the tension stiffening models. For this purpose, the finite element analysis model was used to calculate deflections for the reinforced concrete beams using Scanlon [3], Lin and Scordelis [4], and Owen and Damjanic [5] tension stiffening Models. In this paper, the finite element formulation was based on layered and degenerate shell elements adopted for the three dimensional global analysis of plate type structures [6]. Eight-node isoparametric degenerated element was selected. The layered element was applied to account for the behaviour of the reinforced concrete members, which exhibited difference properties in the thickness direction owing to the placement of reinforcements. The uncracked concrete was assumed as linear elastic material. After cracking, the concrete was treated as orthotropic. As a result, Scanlon's model generally shows good agreement from the comparative analysis for reinforced concrete beams among the several tension stiffening models.

\section{Acknowledgment}

Basic Science Research Program supported this work through the National Research Foundation of Korea (NRF) grant funded by the Korean Government (MINIST) (NRF-2013R1A1A2060436).

\section{References}

[1] S. M. Allam, M. S. Shoukry, G. E. Rashad, and A. S. Hassan, "Evaluation of tension stiffening effect on the crack width calculation of flexural RC memners," Alexandria Engineering Journal, vol. 52, pp. 163-173, 2013.

[2] S. V. T. J. Perera and H. Mutsuyoshi, "Tension stiffening behaviour of high-strength concrete tension members," Annual Research Journal of SLSAJ, vol. 11, pp. 10-18, 2011.

[3] A. Scanlon, "Time dependent deflections of reinforced concrete slabs," Ph.D. thesis, University of Alberta, Canada, 1972.

[4] C. S. Lin and A. C. Scordelis, "Nonlinear analysis of RC shell of general form," Journal of the Structural Division, ASCE, pp. 523-538, 1975.

[5] F. Damjanic, E. Hinton, and D. R. J. Owen, "Analysis and design of concrete structures Part 1," in Proceedings of the International Concrete on Computer-Aided, Swansea, U. K., 1984, pp. 693-706.

[6] M. S. Kim, "Probabilistic Analysis of Concrete Flat Plates for Deflection Control," Ph.D. thesis, Kyung Hee University, Korea, 2013 